\title{
Abdominal wall defects
}

\section{Christina M. Bence, Amy J. Wagner}

Division of Pediatric Surgery, Department of Surgery, Medical College of Wisconsin, Milwaukee, WI, USA

Contributions: (I) Conception and design: A Wagner; (II) Administrative support: C Bence; (III) Provision of study materials or patients: All authors; (IV) Collection and assembly of data: C Bence; (V) Data analysis and interpretation: C Bence; (VI) Manuscript writing: All authors; (VII) Final approval of manuscript: All authors.

Correspondence to: Amy J. Wagner, MD. Division of Pediatric Surgery, Children's Hospital of Wisconsin, 999 North 92nd Street, Suite CCC 320, Milwaukee, WI 53226, USA. Email: awagner@chw.org.

\begin{abstract}
Abdominal wall defects are common congenital anomalies with the most frequent being gastroschisis and omphalocele. Though both are the result of errors during embryologic development of the fetal abdominal wall, gastroschisis and omphalocele represent unique disorders that have different clinical sequelae. Gastroschisis is generally a solitary anomaly with postnatal outcomes related to the underlying integrity of the prolapsed bowel. In contrast, omphalocele is frequently associated with other structural anomalies or genetic syndromes that contribute more to postnatal outcomes than the omphalocele defect itself. Despite their embryological differences, both gastroschisis and omphalocele represent anomalies of fetal development that benefit from multidisciplinary and translational approaches to care, both pre- and postnatally. While definitive management of abdominal wall defects currently remains in the postnatal realm, advancements in prenatal diagnostics and therapies may one day change that. This review focuses on recent advancements, novel techniques, and current controversies related to the prenatal diagnosis and management of gastroschisis and omphalocele.
\end{abstract}

Keywords: Abdominal wall defects; gastroschisis; omphalocele

Submitted Mar 09, 2020. Accepted for publication Aug 14, 2020.

doi: $10.21037 /$ tp-20-94

View this article at: http://dx.doi.org/10.21037/tp-20-94

\section{Introduction}

The two most common congenital abdominal wall defects are gastroschisis and omphalocele. Both have reported incidences around 1 in 4,000 live births, however the incidence of omphalocele identified on second-trimester ultrasound is as high as 1 in 1,100 highlighting the significant rate of associated intrauterine fetal demise (1-4). In contrast, the incidence of gastroschisis specifically has increased world-wide over the last few decades. This increase is not entirely understood, though socioeconomic status and environmental factors have been postulated as potential contributors (5). Both omphalocele and gastroschisis are commonly diagnosed prenatally, and each has an associated spectrum of postnatal outcomes that can range from a brief neonatal intensive care unit (NICU) stay to life-long functional limitations or even death. Outcomes for neonates with gastroschisis are generally dependent on the characteristics of the abdominal wall defect and underlying bowel viability, while omphalocele outcomes are determined by both defect size and the presence of other associated anomalies (5-8). Because of the dependence on prenatal diagnostics and the broad spectrum of postnatal 
outcomes associated with these defects, gastroschisis and omphalocele are excellent examples of fetal anomalies that require multidisciplinary and translational approaches to patient care. This review focuses on recent advancements, novel techniques, and current controversies related to the prenatal diagnosis and management of gastroschisis and omphalocele.

\section{Gastroschisis}

\section{Background}

The abdominal wall defect of gastroschisis occurs to the right side of the umbilicus and is by definition lacking a protective covering over the herniated abdominal contents. Though not entirely understood, it is thought to be due to a disruption in migration of the lateral ventral body folds early in embryonal development, creating a para-midline defect. In normal development, the elongating intestine herniates outside of the abdominal cavity around the sixth week of gestation, and then over the next four weeks undergoes a process of midgut rotation with return of the intestines to the abdomen (2). However, if the abdominal wall fails to form completely, the intestine can remain herniated into the amniotic cavity.

Gastroschisis is not frequently associated with other anomalies. Postnatal outcomes are related to degree of intestinal injury and subsequent gastrointestinal complications. Broadly, gastroschisis can be divided into two types-simple and complex. Complex gastroschisis is defined as any associated intestinal atresia, necrosis, perforation, or volvulus, while simple gastroschisis lacks any intestinal complications (4-6). Complex gastroschisis is associated with a higher mortality rate, prolonged hospital stays, increased infectious complications, and greater risk of intestinal failure (2). Another predictor of mortality and worse postnatal outcomes is the presence of liver herniation in gastroschisis. Retrospective review of gastroschisis patients at a single institution over a 15 -year period found a $6 \%$ rate of liver herniation, which was associated with $57 \%$ mortality and poor outcomes overall (9). The prenatal workup and management of pregnancies complicated by gastroschisis include predictive risk stratification and close monitoring for fetal distress or demise.

\section{Prenatal diagnosis, surveillance, and prognosis}

Gastroschisis is currently diagnosed prenatally in over
$90 \%$ of cases (10). Identification of free-floating intestines outside of the abdominal cavity to the right of a normallyinserted umbilical cord on prenatal ultrasound is diagnostic. Prenatal diagnosis most frequently occurs during the second trimester, though has been reported as early as the twelfth week of gestation. A diagnosis of gastroschisis made during the first trimester must be interpreted with caution and confirmed later in gestation, however, as normal visceral rotation may not be completed until the end of the first trimester (11). Once gastroschisis has been identified, referral to a multidisciplinary fetal center is recommended for close fetal surveillance, delivery planning, and high-level neonatal care. Though no specific guidelines for prenatal gastroschisis surveillance exist, a recent North American Fetal Therapy Network (NAFTNet) survey assessed current monitoring practices for gastroschisis among participating maternal-fetal medicine (MFM) specialists (12). In stable patients, antenatal testing with a combination of nonstress test, biophysical profile, and sonographic amniotic fluid index most commonly began at 32 weeks gestation and was repeated weekly. The necessity of such close surveillance is related to the high incidence of spontaneous intrauterine fetal demise, which has been prospectively identified as $4.5 \%$ in fetuses with gastroschisis compared to $0.6 \%$ in non-anomalous fetuses and may be increased throughout the third trimester (13-15). Further, intrauterine growth restriction is common in gastroschisis and should be monitored closely during gestation (12).

Another contemporaneous reason for focused and repeated prenatal evaluation of fetuses with gastroschisis is attempted antenatal prediction of complex gastroschisis and associated adverse neonatal outcomes. This predictive ability is necessary for MFM specialists to provide recommendations regarding delivery planning, and for more accurate prognostication and counseling of families. Multiple recent studies have evaluated different antenatal sonographic factors with discrepant results, often due to small sample sizes and inconsistent definitions/documentation. The factors identified on multi-institutional review and meta-analyses that correlate with complex gastroschisis include intra-abdominal bowel dilation (especially when repeatedly present during fetal development) and polyhydramnios $(10,16)$. Further, gastric dilation, increased abdominal distention, intrauterine growth restriction, and extra-abdominal bowel dilation identified on antenatal ultrasound were found to be predictive of adverse neonatal outcomes (16,17). More work is needed to prospectively validate these results, and to 

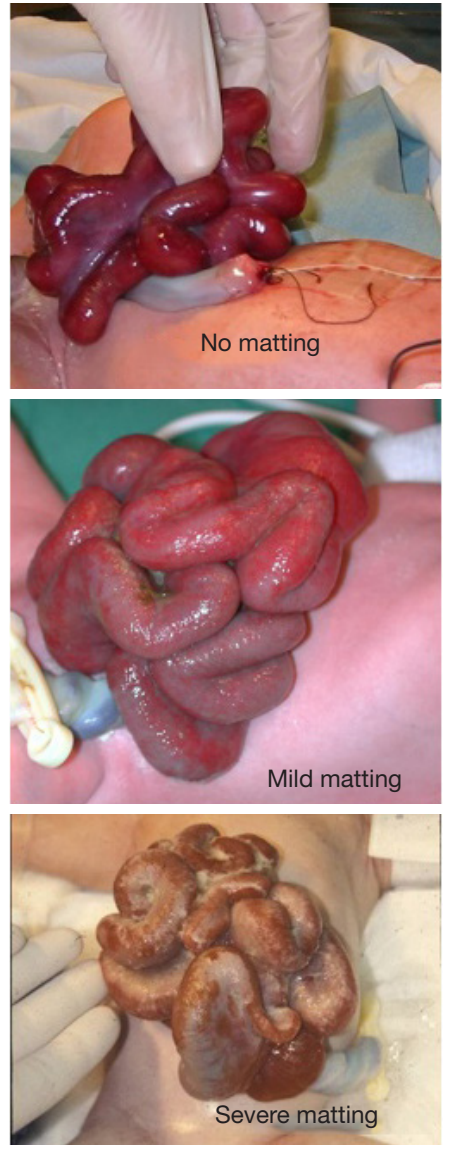

Figure 1 Pictorial representation of the spectrum of bowel inflammation or "matting" (none, mild, or severe) that can be seen in gastroschisis patients. Used with permission from The Canadian Pediatric Surgery Network website (http://www.capsnetwork.org/ portal/ForAbstractorsSiteInvestigators/EducationfortheGSBowelI njuryScore.aspx)

determine the predictive value of multiple factors combined.

\section{Prenatal management}

\section{Delivery planning}

Another area of controversy in the management of gastroschisis patients is the ideal timing of delivery. Overall the average gestational age at spontaneous delivery in gastroschisis is $<37$ weeks, and some postulate that late preterm, planned delivery could result in improved outcomes (18). As discussed above, there is a high incidence of spontaneous intrauterine fetal demise in gastroschisis pregnancies compared to non-anomalous pregnancies and this risk may increase approaching term gestation $(13,15)$. Further, gastroschisis is associated with variable degrees of bowel inflammation/thickening termed "matting" that is identified at birth and has been hypothesized to be due to the inflammatory nature of amniotic fluid on exposed bowel (Figure 1). The degree of bowel matting identified at birth has been found to be predictive of worse neonatal outcomes (18). Another consideration when determining the ideal timing of delivery in gastroschisis is the risk of vanishing gastroschisis, or closure of the abdominal wall defect around herniated bowel resulting in devastating midgut necrosis, which may increase as pregnancy progresses. Taking these concerns together, some clinicians advocate for early delivery $(<37$ weeks gestation) at varying gestational ages for fetuses with gastroschisis in an attempt to minimize fetal demise and neonatal morbidity $(19,20)$. However early delivery is not without its own potential risks, mainly related to the physiologic immaturity associated with preterm birth. Potential risks include increased mortality, respiratory morbidity, neurocognitive deficits, cholestasis, and sepsis $(20,21)$. Further, a recent Canadian Pediatric Surgery Network (CAPSNet) review found that the degree of bowel matting at birth is inversely associated with gestational age in gastroschisis patients, lending more strength to the argument that elective term delivery ( $\geq 37$ weeks gestation) should be preferred (22). A Cochrane review was unable to draw any conclusions regarding delivery timing for gastroschisis as no large, adequately powered studies were available for review (23). A recent randomized controlled trial (RCT) comparing early delivery (34 weeks gestation) to routine obstetric care was stopped early due to a significantly elevated rate of sepsis in the early delivery group (24). Another RCT is currently underway that will compare delivery at 35 weeks gestation to 38 weeks, and also includes a prospective long-term database and biobank (25). At this time, the published data available do not definitively conclude the ideal timing of delivery in gastroschisis.

The preferred mode of delivery-vaginal versus cesarean section-for fetuses with gastroschisis has also been controversial. However, most data comparing the two delivery methods support the hypothesis that vaginal delivery is as safe as cesarean section in gastroschisis patients, and a recent meta-analysis failed to demonstrate a difference in outcomes between the two methods of delivery (26). Currently accepted practice is to proceed with vaginal 
delivery unless there is another indication for cesarean.

\section{Novel therapies}

With advancements in fetal surgery and the ability to perform in utero procedures during gestation, several innovative therapies have been introduced over the last decade with the goal of improving outcomes in gastroschisis after delivery. A common theme to this work is the hypothesis that reducing the degree to which herniated bowel is in contact with amniotic fluid will improve its function after birth. Both animal and human studies have identified high levels of inflammatory mediators such as ferritin and cytokines (interleukin-6, interleukin-8, tumor necrosis factor) as well as digestive compounds (e.g., lipase and bile acids) in the amniotic fluid of pregnancies complicated by gastroschisis $(27,28)$. Further, this inflammatory milieu is believed to be the cause of the characteristic bowel matting identified after birth. The degree of bowel matting, in addition to the presence or absence of intestinal atresia, perforation, or necrosis, has been used to generate a "gastroschisis prognostic score" (GPS) postnatally (18). The GPS is a predictive marker for increased risk of mortality and morbidity, and higher GPS scores have been shown to correlate with poor outcomes in gastroschisis patients $(18,29)$.

One attempt at minimizing the inflammatory effect of amniotic fluid was the amnioexchange procedure. Amnioexchange involves removal of amniotic fluid during gestation and replacement with the same volume of sterile saline (30). Animal models demonstrated a significant decrease in the presence of inflammatory mediators following amnioexchange, and so the procedure was attempted on human fetuses with gastroschisis. Unfortunately, the RCT was stopped early due to a higher fetal mortality rate in the amnioexchange arm, and interim results demonstrated that although there was an initial decrease in inflammatory and digestive compounds present within the amniotic fluid following the procedure, this effect was lost over time (31). Amnioexchange is not currently recommended as a potential treatment option for gastroschisis.

Another novel approach to prenatal treatment of gastroschisis is fetoscopic intervention via either intestinal coverage with a synthetic bag (similar to silo placement) or closure of the defect in utero. A fetal lamb model has been developed to test this innovative approach (32). Early studies demonstrated proof of concept, with reduced inflammatory "peel" formation identified in fetal lambs that had complete coverage of their iatrogenic gastroschisis defects compared to those that had no or partial coverage (33). Attempts at fetoscopic bag coverage and closure have so far been technically unsuccessful, however open fetal repair was successful in two lambs and both fetuses survived to term (34-36). This novel technique is still being developed and has exciting potential implications for future prenatal management of gastroschisis.

The newest approach to prenatal gastroschisis coverage involves the use of mesenchymal stem cells. This technique is termed transamniotic stem cell therapy, or TRASCET (37). The theory behind TRASCET is that through augmentation of the biologic role of native stem cells within the amniotic fluid, targeted tissue repair can be achieved. Intra-amniotic delivery of amniotic fluid-derived mesenchymal stem cells (afMSCs) has been demonstrated to successfully induce partial or complete coverage of experimental myelomeningocele defects (37). The same theoretical benefit is now being explored for gastroschisis defects as well, with early results demonstrating sitespecific homing of afMSCs to areas of intestine exclusively exposed to amniotic fluid following TRASCET (38). These examples of novel prenatal interventions for gastroschisis show great promise for the future management of these patients.

\section{Omphalocele}

\section{Background}

In contrast to gastroschisis, the omphalocele defect occurs at the abdominal midline and involves the umbilical ring, resulting in a 3-layer sac encasing the herniated abdominal contents. This sac consists of an inner layer of peritoneum, middle layer of Wharton's jelly, and outer layer of amnion. Embryologically, omphalocele is thought to be the result of a folding defect that occurs as the bowel is returning to the abdominal cavity during normal development (1). The omphalocele defect can range widely in size and type of abdominal viscera present within the sac depending on when during gestation the arrest in bowel rotation occurs. Postnatal outcomes in infants with omphalocele are predominantly dependent on other concurrent anomalies or comorbidities associated with larger-sized defects. Concurrent congenital anomalies can be present in up to $40-80 \%$ of omphalocele cases and most commonly include chromosomal (15-57\%), cardiac (11-23\%), genitourinary 


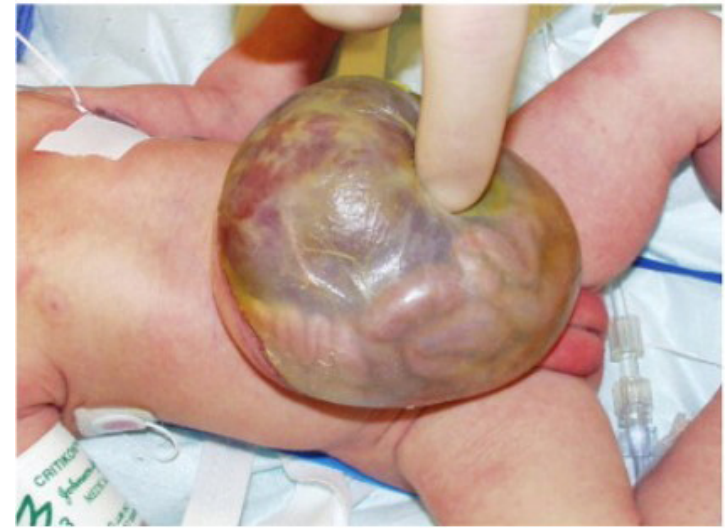

Figure 2 Image depicting a giant omphalocele containing bowel and a portion of liver. Used with permission from Whitehouse JS, Gourlay DM, Masonbrink AR, et al. Conservative management of giant omphalocele with topical povidone-iodine and its affect on thyroid function. 7 Pediatr Surg 2010;45:1192-7.

(6-21\%), musculoskeletal (21\%), gastrointestinal (7-19\%), and neurologic (4-8\%) abnormalities (39-41). Omphalocele can also be associated with certain genetic syndromes, such as Beckwith-Wiedemann, pentalogy of Cantrell, and cloacal extrophy. A recent review of respiratory comorbidities in omphalocele patients identified respiratory insufficiency as an independent predictor of mortality. Specifically, underlying pulmonary hypoplasia and pulmonary hypertension, which are typically seen with large defects that restrict thoracic domain and alter diaphragmatic function, are associated with worse long-term outcomes in omphalocele patients (8). Comprehensive prenatal workup of both the omphalocele itself as well as any associated anomalies or comorbidities is critically important to continued surveillance, prognostication, counselling, and ultimate management.

\section{Prenatal diagnosis, screening, and prognosis}

Similarly to gastroschisis, omphalocele is typically diagnosed on prenatal ultrasound. Diagnostic findings include herniated abdominal contents along the abdominal midline (epigastric, umbilical, or hypogastric locations) covered by a three-layer sac $(1,42)$. The timing of prenatal diagnosis for omphalocele has shifted over the last two centuries from near-universal identification within the second trimester to almost half being identified during the late first trimester (11-14 weeks gestation) $(42,43)$. As mentioned earlier, there is an increased incidence of prenatal demise also associated with omphalocele. This significant prenatal mortality is likely due to a combination of spontaneous abortions and elective pregnancy terminations, especially when other significant anomalies are concurrently identified $(7,41,42)$. Once a diagnosis of omphalocele is made, referral to a fetal care center is recommended to establish a multidisciplinary team of obstetricians, pediatric surgeons, and neonatologists. This team will determine a plan for prenatal surveillance, delivery, and postnatal care based on the characteristics of the omphalocele defect and any associated anomalies.

Comprehensive prenatal ultrasonography along with fetal echocardiogram allow for evaluation of other structural defects and are critical components of the prenatal workup for omphalocele. In addition, fetal karyotyping is offered to provide information on associated chromosomal anomalies. The most common of these include Trisomies 18, 13, and 21; Turner syndrome; and triploidy (41). One study found the elective pregnancy termination rate to be $74 \%$ (compared to an $18 \%$ rate of spontaneous fetal demise) in pregnancies complicated by omphalocele in addition to a known chromosomal abnormality (41).

Prenatal ultrasound is being increasingly used as a means to assist in prognostication depending on specific sonographic characteristics of the omphalocele defect. In general, omphaloceles are classified as either small, giant, or ruptured (Figure 2). The smallest and least morbid defects are sometimes referred to as hernias of the umbilical cord, in which the lateral body folds seem to form correctly during embryologic development, however a portion of small bowel fails to return to the abdominal cavity via the intact umbilical ring. This results in a small hernia located at the base of the umbilical cord at birth (44). These minor defects (described as less than 1.5-4 cm depending on the source) are infrequently associated with other congenital anomalies and do not contain any portion of liver, thereby distinguishing them from larger omphalocele defects in which the abdominal wall musculature is disrupted to a greater degree and higher morbidity is expected $(2,44,45)$. Ruptured omphalocele, though rare, is associated with the highest morbidity, and is defined by disruption of the protective omphalocele sac (46). It can be difficult to distinguish a ruptured omphalocele from gastroschisis, however the presence of an intact umbilical cord remote from a right-sided abdominal wall defect is diagnostic of gastroschisis.

Current controversy exists over the appropriate definition of giant omphalocele. The utility of distinguishing between 


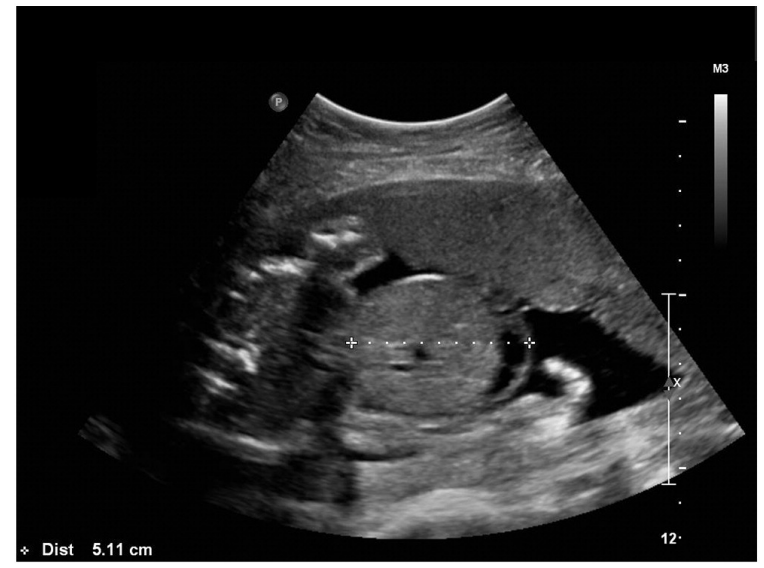

Figure 3 Image depicting measurement of omphalocele diameter on prenatal ultrasound. Used with permission from Fawley JA, Peterson EL, Christensen MA, et al. Can omphalocele ratio predict postnatal outcomes? F Pediatr Surg 2016;51:62-6.

small and giant omphaloceles relates to delivery planning, prognostication, and postnatal repair of the defect. Larger omphalocele defects put infants at higher risk of other associated medical comorbidities, such as pulmonary hypoplasia, chronic lung disease, feeding difficulties, prolonged hospital stays, and increased mortality $(47,48)$. Giant omphaloceles are independently associated with higher morbidity and worse long-term outcomes than small omphaloceles, generally due to lack of abdominal domain and associated pulmonary insufficiency that are common with larger defects $(8,49)$. Classic consensus recognized small omphaloceles as having a defect size $<5 \mathrm{~cm}$ at birth without any portion of the liver present within the omphalocele sac. Defects greater than $5 \mathrm{~cm}$ with liver at least partially protruding were generally considered "giant" and closure was typically delayed (48). However, controversy exists regarding the specific size cut-off of 5 $\mathrm{cm}$ (as outcomes likely depend more on the relative volume of the omphalocele contents in relation to the size of the abdominal cavity) as well as the amount of protruding liver necessary to make a diagnosis of giant omphalocele (50-52). Further, using a size cut-off for diagnosis limits the ability to identify giant omphaloceles prenatally as the size of the fetal abdomen (and by extension the size of the omphalocele defect) changes over the course of gestation.

In general, small omphaloceles can be closed primarily after birth while giant omphaloceles require delayed or staged closure to prevent poor outcomes associated with inadequate abdominal domain (2). The main concerns associated with immediate primary closure of larger omphalocele defects are abdominal compartment syndrome due to inadequate abdominal domain, hepatic artery compression following reduction of an extracorporeal liver, and lack of adequate skin coverage. Staged closure techniques for giant omphalocele include placement of fascial bridging mesh with serial mesh excisions, silo placement followed by serial reductions, raising of skin flaps, and vacuum-assisted closure (2). Another contemporary option for giant omphalocele repair is delayed closure following a period of escharification. This option is colloquially termed the "paint and wait" approach, as a number of different agents can be "painted" onto the omphalocele sac (including silver sulfadiazine, povidoneiodine solution, topical antibacterial ointments, and silverimpregnated solutions), allowing for escharification and epithelialization of the sac and eventual repair of the resulting ventral hernia at a later date $(2,53)$. A recent area of study has focused on identifying prenatal factors in omphalocele pregnancies that predict type or timing of postnatal surgical closure. The fetal omphalocele ratio is the proportional measurement of omphalocele circumference (or diameter alternatively) to either abdominal circumference or head circumference identified on prenatal ultrasound, and has been demonstrated in various iterations to predict type of surgical closure (primary vs. staged/ delayed) and outcomes in multiple cohorts (Figure 3) $(47,48,54-56)$. The underlying principle of these ratios is to determine the "viscero-abdominal disproportion" between the contents of the omphalocele sac and the fetal abdomen $(47,48)$. These measurements are already being utilized at some fetal centers to aid in prenatal prognostication and family counseling for pregnancies complicated by omphalocele.

Fetal magnetic resonance imaging (MRI) is another diagnostic tool that may have utility in the prenatal workup of omphalocele. Respiratory insufficiency related to low lung volumes and associated pulmonary hypoplasia in the setting of large omphalocele defects is a major contributor to infant morbidity and prolonged hospital stay. Contemporary data has shown that low observed/expected ratios of fetal lung volume identified on MRI are predictive of increased postnatal mortality, morbidity, and hospital length of stay $(57,58)$.

\section{Prenatal management}

In comparison to gastroschisis, the delivery recommendations 
for omphalocele are somewhat less controversial. First and foremost, the family should meet with members of the multidisciplinary fetal care team to discuss findings identified on prenatal workup and to determine if continuation of the pregnancy is desirable. In the setting of other associated structural or chromosomal anomalies, the decision to electively terminate an omphalocele pregnancy can be as high as $75 \%$ (41). If delivery planning is desired, the ideal timing of delivery should be determined. Currently there are no data to suggest that preterm delivery is advantageous for omphalocele, unless there is another indication for earlier delivery (42). Route of delivery, however, is dictated by the size of the omphalocele sac and whether or not the liver is located extracorporeally. In general, studies that have compared outcomes following vaginal delivery and cesarean section have combined all sizes and types of omphaloceles and have been limited by small sample sizes (59). These data demonstrated no associations between mode of delivery and postnatal outcomes. However, in very large defects, cases of sac rupture during vaginal delivery have been reported $(46,59,60)$. Because of these findings and the concern for hepatic compression when a significant portion of the liver is extracorporeal, most clinicians recommend cesarean delivery in the setting of giant omphalocele.

\section{Conclusions}

Gastroschisis and omphalocele are common congenital abdominal wall defects. Though they represent different embryological outcomes, both rely on accurate prenatal diagnosis and referral to a multidisciplinary fetal center. The prenatal management strategies of gastroschisis and omphalocele are nuanced and continually evolving with new technology and large-scale data. Though definitive treatment for congenital abdominal wall defects currently remains in the postnatal realm, advancements in fetal surgery may one day change that.

\section{Acknowledgments}

Funding: None.

\section{Footnote}

Provenance and Peer Review: This article was commissioned by the Guest Editors (Eric B. Jelin and George B. Mychaliska) for the series "Fetal Surgery" published in Translational
Pediatrics. The article was sent for external peer review organized by the Guest Editors and the editorial office.

Conflicts of Interest: Both authors have completed the ICMJE uniform disclosure form (available at http://dx.doi. org/10.21037/tp-20-94). The series "Fetal Surgery" was commissioned by the editorial office without any funding or sponsorship. The authors have no other conflicts of interest to declare.

Ethical Statement: The authors are accountable for all aspects of the work in ensuring that questions related to the accuracy or integrity of any part of the work are appropriately investigated and resolved.

Open Access Statement: This is an Open Access article distributed in accordance with the Creative Commons Attribution-NonCommercial-NoDerivs 4.0 International License (CC BY-NC-ND 4.0), which permits the noncommercial replication and distribution of the article with the strict proviso that no changes or edits are made and the original work is properly cited (including links to both the formal publication through the relevant DOI and the license). See: https://creativecommons.org/licenses/by-nc-nd/4.0/.

\section{References}

1. Christison-Lagay ER, Kelleher CM, Langer JC. Neonatal abdominal wall defects. Semin Fetal Neonatal Med 2011;16:164-72.

2. Islam S. Congenital Abdominal Wall Defects. In: Holcomb GW III, Murphy JP SPS, editor. Holcomb Ashcraft's Pediatr. Surgery, IV. 7th ed. Philadelphia, PA: Elsevier Saunders, 2020:763-79.

3. Prefumo F, Izzi C. Fetal abdominal wall defects. Best Pract Res Clin Obstet Gynaecol 2014;28:391-402.

4. Gamba P, Midrio P. Abdominal Wall Defects: Prenatal Diagnosis, Newborn Management, and Long-Term Outcomes. Semin Pediatr Surg 2014;23:283-90.

5. Skarsgard ED. Management of gastroschisis. Curr Opin Pediatr 2016;28:363-9.

6. O'Connell RV, Dotters-Katz SK, Kuller JA, et al. Gastroschisis: A Review of Management and Outcomes. Obstet Gynecol Surv 2016;71:537-44.

7. Conner P, Vejde JH, Burgos CM. Accuracy and impact of prenatal diagnosis in infants with omphalocele. Pediatr Surg Int 2018;34:629-33.

8. Duggan E, Puligandla PS. Respiratory disorders in patients 
with omphalocele. Semin Pediatr Surg 2019;28:115-7.

9. McClellan EB, Shew SB, Lee SS, et al. Liver herniation in gastroschisis: Incidence and prognosis. J Pediatr Surg 2011;46:2115-8.

10. Lap CCMM, Pistorius LR, Mulder EJH, et al. Ultrasound markers for prediction of complex gastroschisis and adverse outcome: longitudinal prospective nationwide cohort study. Ultrasound Obstet Gynecol 2020;55:776-85.

11. Oakes MC, Porto M, Chung JH. Advances in prenatal and perinatal diagnosis and management of gastroschisis. Semin Pediatr Surg 2018;27:289-99.

12. Amin R, Domack A, Bartoletti J, et al. National Practice Patterns for Prenatal Monitoring in Gastroschisis: Gastroschisis Outcomes of Delivery (GOOD) Provider Survey. Fetal Diagn Ther 2019;45:125-30.

13. Meyer MR, Shaffer BL, Doss AE, et al. Prospective risk of fetal death with gastroschisis. J Matern Fetal Neonatal Med 2015;28:2126-9.

14. South AP, Stutey KM, Meinzen-Derr J. Metaanalysis of the prevalence of intrauterine fetal death in gastroschisis. Am J Obstet Gynecol 2013;209:114.e1-13.

15. Sparks TN, Shaffer BL, Page J, et al. Gastroschisis: mortality risks with each additional week of expectant management. Am J Obstet Gynecol 2017;216:66.e1-66.e7.

16. D'Antonio F, Virgone C, Rizzo G, et al. Prenatal risk factors and outcomes in gastroschisis: A meta-analysis. Pediatrics 2015;136:e159-69.

17. Page R, Ferraro ZM, Moretti F, et al. Gastroschisis: Antenatal sonographic predictors of adverse neonatal outcome. J Pregnancy 2014;2014:239406.

18. Cowan KN, Puligandla PS, Laberge JM, et al. The gastroschisis prognostic score: Reliable outcome prediction in gastroschisis. J Pediatr Surg 2012;47:1111-7.

19. Lausman AY, Langer JC, Tai M, et al. Gastroschisis: what is the average gestational age of spontaneous delivery? J Pediatr Surg 2007;42:1816-21.

20. Landisch RM, Yin Z, Christensen M, et al. Outcomes of gastroschisis early delivery: A systematic review and metaanalysis. J Pediatr Surg 2017;52:1962-71.

21. McIntire DD, Leveno KJ. Neonatal mortality and morbidity rates in late preterm births compared with births at term. Obstet Gynecol 2008;111:35-41.

22. Youssef F, Laberge JM, Baird RJ; Canadian Pediatric Surgery Network (CAPSNet). The correlation between the time spent in utero and the severity of bowel matting in newborns with gastroschisis. J Pediatr Surg 2015;50:755-9.

23. Grant NH, Dorling J, Thornton JG. Elective preterm birth for fetal gastroschisis. Cochrane Database Syst Rev
2013;(6):CD009394.

24. Shamshirsaz AA, Lee TC, Hair AB, et al. Elective delivery at 34 weeks vs routine obstetric care in fetal gastroschisis: randomized controlled trial. Ultrasound Obstet Gynecol 2020;55:15-9.

25. ClinicalTrials.gov. Gastroschisis Outcomes of Delivery (GOOD) Study. Natl Libr Med 2017. (accessed March 9, 2020). Available online: https://clinicaltrials.gov/ct2/show/ study/NCT02774746

26. Kirollos DW, Abdel-Latif ME. Mode of delivery and outcomes of infants with gastroschisis: a meta-analysis of observational studies. Arch Dis Child Fetal Neonatal Ed 2018;103:F355-63.

27. Burc L, Volumenie JL, de Lagausie P, et al. Amniotic fluid inflammatory proteins and digestive compounds profile in fetuses with gastroschisis undergoing amnioexchange. BJOG 2004;111:292-7.

28. Guibourdenche J, Berrebi D, Vuillard E, et al. Biochemical investigations of bowel inflammation in gastroschisis. Pediatr Res 2006;60:565-8.

29. Puligandla PS, Baird R, Skarsgard ED, et al. Outcome prediction in gastroschisis - The gastroschisis prognostic score (GPS) revisited. J Pediatr Surg 2017;52:718-21.

30. Luton D, Guibourdenche J, Vuillard E, et al. Prenatal management of gastroschisis: The place of the amnioexchange procedure. Clin Perinatol 2003;30:551-viii.

31. Luton D, Mitanchez D, Winer N, et al. A randomised controlled trial of amnioexchange for fetal gastroschisis. BJOG 2019;126:1233-41.

32. Bergholz R, Krebs T, Wenke K, et al. Abdominal wall incision with or without exteriorization of bowel: Results from a fetal lamb model for the embryogenesis of gastroschisis. Fetal Diagn Ther 2013;33:55-60.

33. Krebs T, Boettcher M, Schäfer H, et al. Gut inflammation and expression of ICC in a fetal lamb model of fetoscopic intervention for gastroschisis. Surg Endosc 2014;28:2437-42.

34. Bergholz R, Krebs T, Cremieux B, et al. Fetoscopic techniques for prenatal covering of gastroschisis in an ovine model are technically demanding and do not lead to permanent anchoring on the fetus until the end of gestation. Surg Endosc 2021;35:745-53.

35. Bergholz R, Krebs T, Wenke K, et al. Fetoscopic management of gastroschisis in a lamb model. Surg Endosc 2012;26:1412-6.

36. Stephenson JT, Pichakron KO, Vu L, et al. In utero repair of gastroschisis in the sheep (Ovis aries) model. J Pediatr Surg 2010;45:65-9.

37. Fauza DO. Transamniotic stem cell therapy: A novel 
strategy for the prenatal management of congenital anomalies. Pediatr Res 2018;83:241-8.

38. Chalphin AV, Tracy SA, Kycia I, et al. Donor mesenchymal stem cell kinetics after transamniotic stem cell therapy (TRASCET) in a rodent model of gastroschisis. J Pediatr Surg 2020;55:482-5.

39. Benjamin B, Wilson GN. Anomalies associated with gastroschisis and omphalocele: Analysis of 2825 cases from the Texas Birth Defects Registry. J Pediatr Surg 2014;49:514-9.

40. Corey KM, Hornik CP, Laughon MM, et al. Frequency of anomalies and hospital outcomes in infants with gastroschisis and omphalocele. Early Hum Dev 2014;90:421-4.

41. Fleurke-Rozema H, van de Kamp K, Bakker M, et al. Prevalence, timing of diagnosis and pregnancy outcome of abdominal wall defects after the introduction of a national prenatal screening program. Prenat Diagn 2017;37:383-8.

42. Verla MA, Style CC, Olutoye OO. Prenatal diagnosis and management of omphalocele. Semin Pediatr Surg 2019;28:84-8.

43. Liang YL, Kang L, Tsai PY, et al. Prenatal diagnosis of fetal omphalocele by ultrasound: A comparison of two centuries. Taiwan J Obstet Gynecol 2013;52:258-63.

44. İnce E, Temiz A, Ezer SS, et al. Poorly understood and often miscategorized congenital umbilical cord hernia: an alternative repair method 2017;21:449-54.

45. Raju R, Satti M, Lee Q, et al. Congenital hernia of cord: An often misdiagnosed entity. BMJ Case Rep 2015;2015:bcr2015209642.

46. Gonzalez KW, Chandler NM. Ruptured omphalocele: Diagnosis and management. Semin Pediatr Surg 2019;28:101-5.

47. Peters NC, Hooft ME, Ursem NT, et al. The relation between viscero-abdominal disproportion and type of omphalocele closure. Eur J Obstet Gynecol Reprod Biol 2014;181:294-9.

48. Peters NCJ, Hijkoop A, Lechner RL, et al. The validity of the viscero-abdominal disproportion ratio for type of surgical closure in all fetuses with an omphalocele. Prenat Diagn 2019;39:1070-9.

49. Baerg JE, Munoz AN. Long term complications

Cite this article as: Bence CM, Wagner AJ. Abdominal wall defects. Transl Pediatr 2021;10(5):1461-1469. doi: 10.21037/ tp-20-94 and outcomes in omphalocele. Semin Pediatr Surg 2019;28:118-21.

50. Danzer E, Gerdes M, D'Agostino JA, et al. Prospective, interdisciplinary follow-up of children with prenatally diagnosed giant omphalocele: short-term neurodevelopmental outcome. J Pediatr Surg 2010;45:718-23.

51. Lee SL, Beyer TD, Kim SS, et al. Initial nonoperative management and delayed closure for treatment of giant omphaloceles. J Pediatr Surg 2006;41:1846-9.

52. van Eijck FC, Hoogeveen YL, van Weel C, et al. Minor and giant omphalocele: long-term outcomes and quality of life. J Pediatr Surg 2009;44:1355-9.

53. Bauman B, Stephens D, Gershone H, et al. Management of giant omphaloceles: A systematic review of methods of staged surgical vs. nonoperative delayed closure. J Pediatr Surg 2016;51:1725-30.

54. Fawley JA, Peterson EL, Christensen MA, et al. Can omphalocele ratio predict postnatal outcomes? J Pediatr Surg 2016;51:62-6.

55. Kleinrouweler CE, Kuijper CF, Van Zalen-Sprock MM, et al. Characteristics and outcome and the omphalocele circumference/abdominal circumference ratio in prenatally diagnosed fetal omphalocele. Fetal Diagn Ther 2011;30:60-9.

56. Montero FJ, Simpson LL, Brady PC, et al. Fetal omphalocele ratios predict outcomes in prenatally diagnosed omphalocele. Am J Obstet Gynecol 2011;205:284.e1-284.e2847.

57. Chock VY, Davis AS, Cho SH, et al. Prenatally diagnosed omphalocele: characteristics associated with adverse neonatal outcomes. J Perinatol 2019;39:1111-7.

58. Danzer E, Victoria T, Bebbington MW, et al. Fetal MRIcalculated total lung volumes in the prediction of shortterm outcome in giant omphalocele: Preliminary findings. Fetal Diagn Ther 2012;31:248-53.

59. Segel SY, Marder SJ, Parry S, et al. Fetal abdominal wall defects and mode of delivery: A systematic review. Obstet Gynecol 2001;98:867-73.

60. Heider AL, Strauss RA, Kuller JA. Omphalocele: clinical outcomes in cases with normal karyotypes. Am J Obstet Gynecol 2004;190:135-41. 